\title{
Simulation in clinical teaching and learning
}

\begin{abstract}
Jennifer M Weller MD, MClinEd, FANZCA Associate Professor

Debra Nestel PhD, Professor

Stuart D Marshal MHumanFact, MRCS FANZCA Lead Researcher and Instructor

Peter M Brooks $M D$, FRACP Director

imulation-based education (SBE) is a rapidly developing discipline that can provide safe and effective learning environments for students. ${ }^{1}$ Clinical situations for teaching and learning purposes are created using mannequins, part-task trainers, simulated patients or computer-generated simulations.

Here, we explore the factors driving the use of SBE, its advantages and disadvantages, the evidence for its effectiveness and its future role in medical education.

\section{Factors driving simulation-based education}

Jennifer J Conn FRACP MClinEd BSc(Hons) Senior Lecturer

1 Centre for Medical and Health Sciences Education, University of Auckland, Auckland, NZ

2 Gippsland Medica School, Monash University, Churchill, VIC

3 Simulation and Skills Centre, Southern Health and Monash University, Monash Medical Centre Melbourne, VIC

4 Australian Health Workforce Institute University of Melbourne Melbourne, VIC

$\mathbf{5}$ Department of Medicine Royal Melbourne Hospital, University of Melbourne Melbourne, VIC.

j.weller@auckland.ac.nz

doi:10.5694/mja10.11474

\begin{abstract}
An abridged version of this article appeared in the printed journal download pdf
\end{abstract}

Series Guest Editor

Jennifer J Conn FRACP, MClinEd, BSc(Hons)

\section{Clinical placements}

Changes in health care delivery and medical education in Australia have presented medical schools with considerable challenges in providing suitable clinical experiences in medical curricula. An almost doubling in student numbers, combined with pressure to increase tertiary hospital productivity, has reduced students' access to hospital patients. The tertiary hospital clinical experience thus no longer meets the needs of the curriculum. In this context, simulated learning environments can contribute to and expand students' opportunities for gaining clinical skills and experience. $^{1,2}$

\section{Patient safety}

An important influence on the use of SBE is the patient safety agenda. Adverse events and resultant patient harm are often attributed to failures in communication and teamwork. Practice in simulated learning environments can reduce some of the underlying causes of adverse events. The Lucian Leape Institute, in its report Unmet needs: teaching physicians to provide safe patient care, ${ }^{3}$ recently urged medical schools to take advantage of the rapidly expanding uses of simulation to equip students with the skills required to protect patient safety.

\section{Educational imperatives}

SBE has the potential to provide greater efficiency and rigour compared with learning through opportunistic clinical experiences. Clinical situations and events can be scheduled, observed and then repeated so learning can be consolidated. SBE can also ensure that students have a degree of clinical competence before exposure to real patients. This has positive implications for both patient safety and training time. Furthermore, SBE can enhance the transfer of theoretical knowledge to the clinical context and ease the transition to the clinical years and into the workforce. ${ }^{2}$ Students can rehearse specific clinical challenges, such as the management of acute heart failure, ${ }^{4}$ and develop the skills needed for

\section{Summary \\ - Simulation-based education (SBE) is a rapidly developing method of supplementing and enhancing the clinical education of medical students. \\ - Clinical situations are simulated for teaching and learning purposes, creating opportunities for deliberate practice of new skills without involving real patients. \\ - Simulation takes many forms, from simple skills training models to computerised full-body mannequins, so that the needs of learners at each stage of their education can be targeted. \\ - Emerging evidence supports the value of simulation as an educational technique; to be effective it needs to be integrated into the curriculum in a way that promotes transfer of the skills learnt to clinical practice. \\ - Currently, SBE initiatives in Australia are fragmented and depend on local enthusiasts; Health Workforce Australia is driving initiatives to develop a more coordinated national approach to optimise the benefits of simulation.}

working in a team (Box 1). While experience with real patients will always be fundamental to developing clinical expertise, there are areas in each domain of medical practice in which instruction can be supported and enhanced by SBE.

\section{Modes of simulation}

Simulation of the clinical environment can be achieved in a variety of ways:

- Full-body mannequins are physical representations of patients. Their complexity varies from being just the physical shape of a patient to incorporating complex electronic equipment for generating physiological responses. In the latter situation, responses can be controlled manually by an operator or programmed into the simulator to model the effects of pathological states and pharmacological interventions.

Part-task trainers are models used for repeated practice of the technical components of a clinical task. Examples include "arms" for practising intravenous cannulation, head and thorax models for practising airway skills and synthetic skin pads for practising suturing.

- Simulated patients, also called "patient actors" or "standardised patients", are individuals trained to behave in a particular way for clinical interactions. ${ }^{5}$ They are extensively used for teaching and assessment in medical education, especially for communication skills acquisition, and can provide constructive feed- 
back to students from the patient perspective. ${ }^{6}$ Specifically trained simulated patients, known as clinical teaching associates, are used in some Australian medical schools to introduce students to sensitive clinical tasks, such as conducting a breast examination or performing a Pap smear. ${ }^{7}$

- Computer-generated simulators are representations of tasks or environments used to facilitate learning. These may be as simple as a computer program to demonstrate the operation of a piece of equipment, such as an anaesthetic machine, ${ }^{8}$ or as complex as a detailed virtual reality environment in which participants interact with virtual patients or other health professionals (for example, Second Life - a 3-D virtual reality environment used to create a simulated learning experience). ${ }^{9,10}$

- Hybrid simulators are a combination of simulated patients with part-task trainers to contextualise learning. For example, a model wound can be attached to a simulated patient so students can learn both the procedural technique and the associated communication skills and professional behaviours. ${ }^{11}$ Similarly, a modified stethoscope when placed on a patient actor can be used to simulate specific clinical signs, such as a heart murmur or abnormal breathing sounds. ${ }^{12}$

\section{Simulation fidelity}

"Fidelity" describes the extent to which a simulation represents reality. It also refers to the psychological effect of "immersion" in the situation, or "being there", and the extent to which the clinical environment is accurately represented. ${ }^{13}$ The degree of realism of a simulation technique, and thus the choice of simulator device, needs to be carefully matched with educational level, as too much realism and complexity can distract students, especially novices, from learning basic skills. ${ }^{14}$ For example, the steps for inserting a urinary catheter may be best learnt first using a part-task trainer where each step can be practised. The realism can then be increased by attaching the model to a simulated patient and adding in the requirement to simultaneously use effective communication skills.

\section{Educational theory underpinning simulation}

A major challenge with teaching and learning in clinical settings is that it is opportunistic and unstructured. This can be overwhelming for students who are often required to attempt tasks for which they are ill-prepared. SBE allows deconstruction of clinical skills into their component parts, so students can be presented with scenarios and tasks appropriate for their stage of learning, thus reducing the cognitive load. ${ }^{15}$ Without the complexities of dealing with real patients, students can focus on mastering basic skills and can more readily abstract principles from their experiences to apply in other settings.

\section{Deliberate practice and feedback}

A key advantage of SBE is the ability to create learning environments that facilitate deliberate practice. ${ }^{16}$ Students can rehearse their clinical skills within a structured

\section{Developing expertise in the management of acute heart failure} Pathophysiology

Interactive demonstration: A mannequin with an electrocardiogram and blood pressure monitor displays tachycardia and low blood pressure. A Swan-Ganz catheter shows that both left atrial pressure and pulmonary capillary wedge pressure are raised and cardiac output is reduced. Oxygen saturation falls as a result of ventilation-perfusion mismatch. A student is asked to give oxygen and a dose of frusemide. The students watch the change in physiological parameters as the treatment takes effect.

\section{Preparatory skills}

Skills station: Students are asked to administer oxygen to a "patient" with hypoxia. They need to assemble oxygen tubing and a mask, connect it to the oxygen outlet, turn on the oxygen and place the mask on the "patient". Mistakes are used as learning opportunities.

\section{Theory to practice}

Pause and discuss: Students are presented with a "patient" with acute heart failure and are asked to initiate treatment. The first student raises the head of the bed and administers oxygen. The instructor stops the scenario and questions the students about their clinical reasoning. The next student then continues the management, inserting an intravenous line and giving frusemide.

\section{Transition to night call}

Immersive simulation: A senior student is called by a nurse to see a "patient" on a ward who is acutely short of breath. They need to gather information, diagnose the problem and begin treatment. They can call for help from their fellow students or from a senior colleague. The instructor manages the simulation remotely, providing input only when necessary. The subsequent debrief focuses on clinical reasoning and decision making in managing a patient who is breathless.

\section{Working with the health care team}

Immersive multidisciplinary simulation: A group of senior medical and nursing students are required to manage a "patient" who has become acutely breathless. The nurses know the ward environment and the "patient's" background. The medical students know about breathlessness. Together they need to piece the story together, come up with a diagnosis and management plan, and implement it. The debrief that follows ensures appropriate knowledge and skills of the condition, and explores issues of communication, understanding of roles and capabilities, task coordination and shared decision making.

framework in a focused and repetitive manner, thereby refining their skills until their performance becomes fluent and instinctive. Within the limitations of timetabling, practice can be distributed over multiple sessions of short duration, which promotes more meaningful learning than intense practice over fewer, but longer, study periods. ${ }^{17}$ Existing knowledge and skills can be built on incrementally, and the complexity of tasks calibrated to cater for different learning rates and styles.

The structured nature of SBE can enhance the quality of feedback to students, an important component of skills development and maintenance. It can also encourage reflective practice, whereby students learn to monitor their own performance. ${ }^{18}$

\section{Evidence for effectiveness of simulation}

Overall, research shows there is a positive relationship between SBE and learning outcomes. Applying Kirkpatrick's framework for evaluating the impact of educational programs (Box 2), ${ }^{19}$ there is growing evidence that using simulation results in participant satisfaction, self-reported increased knowledge and improved performance. ${ }^{20}$

At present, however, there is a paucity of Kirkpatrick level 4 evidence on the impact of SBE on patient outcomes, but studies are now emerging. ${ }^{21-24,25} \mathrm{New}$ approaches to synthesising data from qualitative and quantitative studies $^{26}$ are also adding weight to the evidence reported in the research literature. 


\section{Kirkpatrick's four levels of education evaluation ${ }^{19}$}

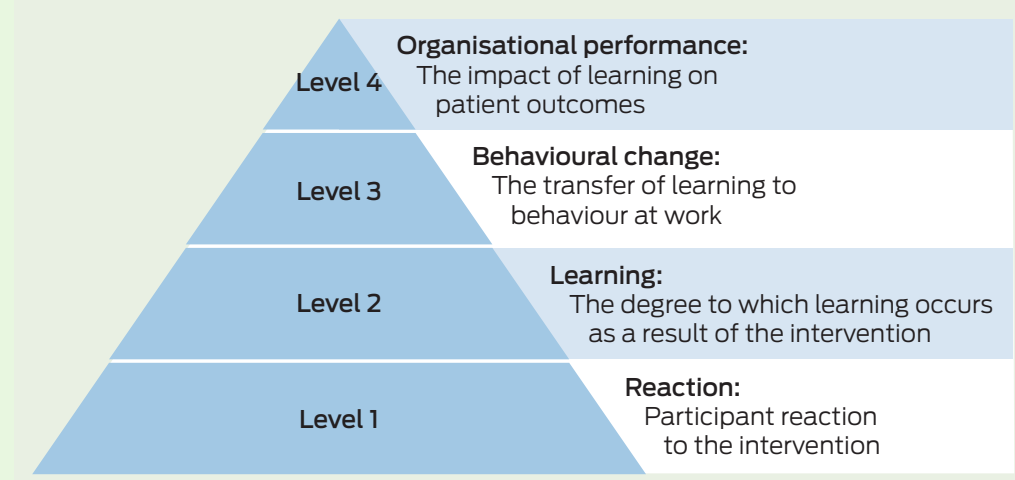

There are two important reasons why there is currently limited high-level evidence for the efficacy of SBE. The first is the wide range of modes of simulation, with limited transferability of evidence between different simulation contexts. Second, SBE is usually embedded within broader curriculum activities, making it difficult for its effects to be isolated from those of other educational interventions. It is in fact unhelpful to separate SBE from other learning methods, as "whole" rather than "isolated" elements are important for learning. Rather, it is the way in which SBE is incorporated into instructional design which determines its effectiveness.

Overall, the evidence at Kirkpatrick levels 1-3 suggests SBE makes a valuable contribution to learning for students, trainees and clinicians, especially for clinical and procedural skills, clinical decision making, patient-centred and interprofessional communication, and teamwork. Some SBE modes, however, are more suited for developing certain types of knowledge, attitudes and skills than others. For example, using virtual patients has been found to be helpful for developing clinical reasoning skills, but can lead to loss of the concept of patient-centred care. ${ }^{27}$

What the evidence also shows is that certain features and best practices need to be incorporated into SBE for it to achieve maximum impact. The twelve important features that optimise SBE are listed in Box 3 and explained in detail in the article by McGaghie et al. ${ }^{20}$

\section{Integrating simulation into the curriculum}

For maximal effectiveness, SBE needs to be integrated into the curriculum and not used as a stand-alone intervention. This is best achieved at the curriculum design phase when educational methods are being identified to meet defined learning objectives. The degree to which SBE can be incorporated into a curriculum will depend on the availability of local resources. ${ }^{28}$ Strategies that promote the transfer of learning from SBE to clinical practice should be considered when integrating SBE into medical curricula are listed in Box 4.

\section{Pitfalls of simulation-based education}

One potential pitfall of SBE is negative learning; inadequate design of the simulator or simulation can give
3 Features and best practices of simulation-based education $^{20}$

- Feedback on performance

- Deliberate practice

- Curriculum integration

- Outcome measurement

- Simulation fidelity

- Skills acquisition and maintenance

- Mastery learning

- Transfer to practice

- Team training

- High-stakes testing

- Instructor training

Educational and professional context

4 Strategies promoting transition from simulation-based education (SBE) to clinical practice

- Align SBE program goals with the needs of individual learners, and with other curriculum goals and activities

- Optimise the timing of SBE interventions to fit with learner needs

- Provide opportunities for repeated practice with feedback and structured learner reflection to broaden the application of SBE to clinical experiences

- Contextualise SBE for immersive simulations by recreating key elements of clinical settings or using simulation in situ

- Provide continuity between simulated and clinical learning environments

- Maintain close working relationships between clinicians, educators and simulation technicians during the development of SBE programs

unintended messages to the learner. If physical signs such as sweating and changes in skin colour are missing, students may start to ignore these signs or consider them unimportant. With simulated events, they may also be tempted to use shortcuts like omitting patient consent and safety procedures. This may lead to habitual unsafe behaviours, such as failure to wear protective gloves and reuse of previously opened bags of intravenous fluids or expired drugs. Students may also learn to communicate in an artificial rather than a genuine manner as a result of interacting with simulated patients.

Another real consideration is the safety of learners. Immersive simulations aim to create a sense of "being there" but may be confronting (such as trauma situations) and leave participants feeling angry, upset, shocked or frustrated. These feelings need to be skilfully managed by appropriate debriefing.

Adequate training of instructors can, to some extent, address these problems, but the additional resources required can be a limiting factor in implementing SBE.

\section{A national strategy for simulation-based education}

Implementation of SBE needs a planned, thoughtful and coordinated approach. Currently, there is no cohesive strategy for simulation education and research in Australia, and successful programs depend to a large degree on local enthusiasts. The findings of the Health Workforce Australia (HWA) report on current and potential use of SBE in 
Australian medical education can be found on the HWA website (www.hwa.gov.au/sites/uploads/simulated-learning-environments-medical-curriculum-report201108.pdf).

Moving teaching away from the bedside reveals the real costs of medical education, with the need for dedicated teaching spaces, equipment and trained teachers. HWA is supporting the use of simulated learning and is providing funding for SBE, including \$46 million capital and \$48 million recurrent funding for 2010-11, and \$20 million recurrent funding per annum subsequently. This funding is for all health care professions and will significantly enhance SBE capability and capacity in Australia, but the challenge to maintain some national cohesion remains. HWA has undertaken a review of opportunities for SBE to enhance efficiency and effectiveness of training of health professionals, and established a mechanism for SBE initiatives to develop capacity across Australia. ${ }^{29}$ HWA has also embarked on the development of a training program for simulation instructors.

The key elements required for an effective national SBE program are infrastructure, curricular integration and trained personnel. A stocktake of existing simulation facilities is needed, followed by a rational development plan to ensure that limited resources are used wisely. The breadth and depth of learning experiences that the different modes of simulation can offer need to be understood, so SBE can be integrated into medical school programs. Critically, there needs to be investment in appropriately trained staff to manage these facilities, as well as training in curriculum development, evaluation and research.

Most health care facilities will want or need some type of simulation facility. The types of simulators and the staff needed to appropriately run facilities are the real issues. A "hub and spoke" model is likely to be the best solution, with major investment being made in communication technology to ensure effective interactions between facilities. Regional networks could be used to coordinate the development of learning programs, usage and research, but should not discourage local initiatives. Purchase of major infrastructure on a shared basis, and regional or national contracts for servicing of equipment may allow some economies of scale. Regional centres or even a national institute for health simulation could coordinate standards for simulation training programs and staff accreditation. $^{30}$

In the United States, the Society for Simulation in Healthcare has gone some way towards developing an approach to accreditation for simulation programs, which could serve as a useful model. ${ }^{31}$ Lessons for further research and development may also be gained from other industries such as defence, aviation and construction.

\section{Future directions}

Simulation technology has rapidly evolved over the past few decades from simple part-task trainers to equipment with haptic feedback technology, as well as complex computer-driven mannequins and virtual reality. The accurate representation of real clinical settings and tasks by more sophisticated devices supports the ongoing development of SBE to help resolve problems in clinical education and health care delivery, especially in the areas of patient safety and assessment.

\section{Education in teamwork and patient safety}

Health care is increasingly being delivered by teams, and the importance of interprofessional education in improving team collaboration is now recognised in medical school education. Newly graduated doctors and nurses describe major barriers in patient care caused by limited understanding of each others' roles, lack of task coordination, and ineffective communication strategies. ${ }^{32}$

Opportunities to undertake teamwork training in real clinical environments are limited. Recent research in simulated settings has shown how information exchanges can be structured to improve communication. ${ }^{33}$ SBE allows both medical students and qualified doctors to learn and practise the skills of leadership, communication, task coordination and cooperation with other health professionals.

\section{Assessment}

The past 10 years have seen a shift towards requiring practitioners to demonstrate competence in key skills - at medical school, vocational training and specialist training levels. Simulation is increasingly being used for these assessments, ${ }^{34}$ including at medical student level. ${ }^{35,36}$ It is likely that competency assessments will become more complex in the future; behavioural aspects and the ability to work in a team will be incorporated into assessments, rather than just technical skills or application of knowledge. There is emerging evidence of the reliability and validity of assessments using simulation for these aspects of medical education. ${ }^{37,38}$

\section{Conclusion}

SBE encompasses a wide spectrum of techniques and there is a growing body of research supporting its value in medical school education. SBE needs to be integrated into medical curricula at the development stage, with careful attention paid to transfer of skills learnt to the real clinical environment. It is crucial that SBE programs are evaluated for their impact on student and patient outcomes. The use of SBE will continue to expand with the evolution of new technologies, but well developed policies are required to ensure coordinated and cost-effective approaches to its wider implementation.

\footnotetext{
Competing interests: No relevant disclosures.

Provenance: Commissioned; externally peer reviewed.

1 Ziv A, Wolpe P, Small S, Glick S. Simulation-based medical education: an ethical imperative. Acad Med 2003; 78: 783-788.

2 Weller J. Simulation in undergraduate medical education: bridging the gap between theory and practice. Med Educ 2004; 38: 32-38.

3 Lucian Leape Institute. Unmet needs: teaching physicians to provide safe patient care. Boston: National Patient Safety Foundation, 2010. http:// www.npsf.org/wp-content/uploads/2011/10/LLI-Unmet-Needs-Report.pdf (accessed Apr 2012).

4 Kneebone RL. Practice, rehearsal, and performance: an approach for simulation-based surgical and procedure training. JAMA 2009; 302:1336-1338.

5 Barrows H. Simulated patients in medical teaching. CMAJ 1968; 98: 674-676.

6 Kneebone R, Arora S, King D, et al. Distributed simulation-accessible immersive training. Med Teach 2010; 32: 65-70.
} 
7 Robertson K, Hegarty K, O'Connor V, Gunn J. Women teaching women's health: issues in the establishment of a clinical teaching associate program for the well woman check. Women Health 2003; 37: 49-65. doi: 10.1300/J013v37n04 05.

8 Lampotang S, Dobbins W, Good ML, et al. Interactive, web-based educational simulation of an anesthesia machine. J Clin Monit Comput 2000; 16: 56-57.

9 Schmidt EA, Scerbo MW, Bliss JP, et al. Surgical skill performance under combat conditions in a virtual environment. Proceedings of the Human Factors and Ergonomics Society 50th Annual Meeting October 2006; 50: 2697-2701. http://pro.sagepub.com/content/50/26/2697.abstract (accessed Apr 2012).

10 Honey MLL, Diener S, Connor K, et al. Teaching in virtual space: Second Life simulation for haemorrhage management [interactive session]. Proceedings Ascilite Auckland 2009; 1222-1224. http://www.ascilite.org.au/conferences/ auckland09/procs/honey-interactive-session.pdf (accessed Apr 2012).

11 Kneebone R, Kidd J, Nestel D, et al. An innovative model for teaching and learning clinical procedures. Med Educ 2002; 36: 628-634.

12 Sprick C, Reynolds KJ, Owen H. SimTools: a new paradigm in high fidelity simulation. Stud Health Technol Inform 2008; 132: 481-483.

13 Beaubien JM, Baker DP. The use of simulation for training teamwork skills in health care: how long can you go? Qual Saf Health Care 2004; 13 Suppl 1: i5l-i56.

14 Maran N, Glavin R. Low- to high-fidelity simulation - a continuum of medical education? Med Educ 2003; 37 Suppl 1: 22-28.

15 van Merriënboer J, Sweller J. Cognitive load theory and complex learning: recent developments and future directions. Educ Psychol Rev 2005; 17: 147-177.

16 Ericsson KA. Deliberate practice and the acquisition and maintenance of expert performance in medicine and related domains. Acad Med 2004; 79 (10 Suppl): S70-S81.

17 Ericsson KA, Krampe RT, Tesch-Römer C. The role of deliberate practice in the acquisition of expert performance. Psychol Rev 1993; 100: 363-406.

18 Mamede S, Schmidt HG. The structure of reflective practice in medicine. Med Educ 2004; 38: 1302-1308.

19 Kirkpatrick DL. Evaluating training programmes: the four levels. San Francisco: Berrett-Koehler, 1994.

20 McGaghie WC, Issenberg SB, Petrusa ER, Scalese RJ. A critical review of simulation-based medical education research, 2003-2009. Med Educ 2010; 44: 50-63.

21 Grantcharov T, Kristiansen V, Bendix J, et al. Randomized clinical trial of virtual reality simulation for laparoscopic skills training. Br J Surg 2004; 91: 146-150.

22 Chaer R, Derubertis B, Lin S, et al. Simulation improves resident performance in catheter-based intervention: results of a randomized, controlled study. Ann Surg 2006; 244: 343-352.
23 Banks E, Pardanani S, King M, et al. A surgical skills laboratory improves residents' knowledge and performance of episiotomy repair. Am J Obstet Gynecol 2006; 195: 1463-1467.

24 Ahlberg G, Hultcrantz R, Jaramillo E, et al. Virtual reality colonoscopy simulation: a compulsory practice for the future colonoscopist? Endoscopy 2005; 37: 1198-1204

25 Frengley R, Weller J, Torrie J, et al. Teaching crisis teamwork: immersive simulation versus case based discussion for intensive care teams. Simulation in Healthcare 2010; 5: 368.

26 Pope C, Mays N, Popay J. Synthesising qualitative and quantitative health evidence. A guide to methods. Part 2, Chapter 5. Mixed approaches to evidence synthesis. Berkshire: McGraw-Hill; Open University Press, 2007: 95.

27 Lepschy A. Communication training. In: Rickheit G, Strohner H, editors. Handbook of communication competence. Berlin: Mouton de Gruyter, 2008: 315-323.

28 Walsh K. Cost effectiveness in medical education. Abingdon, UK: Radcliffe, 2010.

29 Health Workforce Australia. Simulated learning environments [website] http://www.hwa.gov.au/work-programs/clinical-training-reform/simulatedlearning-environments-sles (accessed Apr 2012).

30 Cumin D, Weller JM, Henderson K, Merry AF. Standards for simulation in anaesthesia: creating confidence in our tools. Br J Anaesth 2010; 105: 45-51.

31 Society for Simulation in Healthcare. Council for Accreditation of Healthcare Simulation Programs. https://ssih.org/committees/accreditation (accessed Apr 2012).

32 Weller JM, Barrow M, Gasquoine S. Interprofessional collaboration among junior doctors and nurses in the hospital setting. Med Educ 2011; 45: 478-487.

33 Marshall S, Harrison J, Flanagan B. The teaching of a structured tool improves the clarity and content of interprofessional clinical communication. Oual Saf Health Care 2009; 18: 137-140.

34 Boulet J. Summative assessment in medicine: the promise of simulation for high-stakes evaluation. Acad Emerg Med 2008; 15: 1017-1024.

35 Boulet JR, Murray D, Kras J, et al. Reliability and validity of a simulation-based acute care skills assessment for medical students and residents. Anesthesiology 2003; 99: 1270-1280.

36 Weller J, Robinson B, Larsen P, Caldwell C. Simulation-based training to improve acute care skills in medical undergraduates. N Z Med J 2004; 117: U1119.

37 Weller J, Frengley R, Torrie J, et al. Evaluation of an instrument to measure teamwork in multidisciplinary critical care teams. BMJ Qual Saf 2011; 20: 216222.

38 Weller JM, Robinson BJ, Jolly B, et al. Psychometric characteristics of simulation-based assessment in anaesthesia and accuracy of self-assessed scores. Anaesthesia 2005; 60: 245-250. 